\title{
PERUBAHAN TUTUPAN HUTAN DI TAMAN HUTAN RAYA WAN ABDUL RACHMAN (TAHURA WAR)
}

\section{(FOREST COVER CHANGE IN GREAT FOREST PARK WAN ABDUL RACHMAN)}

\author{
Handoko ${ }^{1)}$ dan Arief Darmawan ${ }^{2)}$ \\ ${ }^{1)}$ Mahasiswa Jurusan Kehutanan Fakultas Pertanian Universitas Lampung, \\ ${ }^{2)}$ Staf Pengajar Jurusan Kehutanan Fakultas Pertanian Universitas Lampung, \\ Jurusan Kehutanan Fakultas Pertanian Universitas Lampung \\ J1. Soemantri Brojonegoro No. 1 Bandar Lampung, 35145 \\ Email : handokoas@gmail.com \\ Phone : 082306608686
}

\begin{abstract}
ABSTRAK
Perubahan tutupan hutan karena penguasaan lahan merupakan ancaman yang serius untuk Taman Hutan Raya Wan Abdul Rachman (Tahura WAR). Penelitian ini bertujuan untuk menganalisis perubahan tutupan hutan pada tahun 1994, 1997, 2000, 2014, dan hal-hal yang terjadi terkait perubahan tutupan lahan di Tahura WAR. Teknik penginderaan jauh dan sistem informasi geografi digunakan untuk memonitor dan mengevaluasi perubahan tutupan lahan hutan yang terjadi sejak tahun 1994 - 2014 dan mengetahui perubahan tutupan hutan yang terjadi pada setiap blok pengelolaan. Data citra satelit landsat tahun 1994, 1997, 2000, 2014 dikumpulkan dan dianalisis. Selanjutnya pengamatan langsung di lapangan dilakukan untuk penilaian akurasi (accuracy assessment) serta studi pustaka untuk melihat kronologi peristiwa yang terkait perubahan hutan tersebut. Hasil penelitian menunjukkan luas hutan pada tahun 1994 adalah 9.090,1 ha atau 40,9\% dari luas keseluruhan Tahura WAR. Pada tahun 2000 tutupan hutan mengalami penurunan tertinggi menjadi $5.428,7$ ha atau $24,4 \%$ dari luas keseluruhan. Tahun 2014 luasan tutupan hutan mengalami peningkatan menjadi 8.953 ha atau $40,2 \%$ dari luas keseluruhan.
\end{abstract}

Kata kunci : klasifikasi citra, perubahan tutupan lahan, Taman Hutan Raya Wan Abdul Rachman

\begin{abstract}
Changes in forest cover due to land tenure is a serious threat to Great Forest Park Wan Abdul Rahman. This study aimed to analyze changes in forest cover in 1994, 1997, 2000, 2014, and the things that happen related to changes in land cover in Great Forest Park Wan Abdul Rahman. Techniques of remote sensing and geographic information systems used to monitor and evaluate changes in forest cover that have occurred since the year 1994 - 2014 and determine forest cover changes that occur in each block management. Landsat satellite image data in 1994, 1997, 2000, 2014 were collected and analyzed. Furthermore, direct observation in the field is done for assessment of accuracy as well as the literature study to look at the chronology of events related to the change of the forest. The results showed forest area in 1994 was 9.090,1 hectare or 40.9\% of the total area Great Forest Park Wan Abdul Rahman. In 2000 the highest forest cover has decreased be 5.428,7 hectare or $24.4 \%$ of the total area. 2014 forest cover has increased to 8.953 hectare or $40.2 \%$ of the total area.
\end{abstract}

Keywords: classification image, land cover change, Great Forest Park Wan Abdul Rachman 


\section{PENDAHULUAN}

\section{Latar Belakang}

Taman Hutan Raya Wan Abdul Rachman (Tahura WAR) merupakan wilayah sistem penyangga kehidupan terutama dalam pengaturan tata air, menjaga kesuburan tanah, mencegah erosi, menjaga keseimbangan iklim mikro, penghasil udara bersih, menjaga siklus unsur hara dan pusat pengawetan keanekaragaman hayati bagi Provinsi Lampung. Selain itu taman hutan raya juga memiliki fungsi pokok sebagai hutan konservasi, yaitu kawasan pelestarian alam untuk tujuan koleksi tumbuhan dan atau satwa yang alami atau buatan, jenis asli dan atau bukan asli, yang dimanfaatkan bagi kepentingan penelitian, ilmu pengetahuan, pendidikan, menunjang budidaya, budaya, pariwisata dan rekreasi. Kondisi penutup lahan di Tahura WAR berdasarkan vegetasinya terdiri dari vegetasi hutan, baik hutan primer maupun hutan sekunder, semak belukar dan alang-alang, juga kebun dan tanaman pertanian atau agroforestri (Dinas Kehutanan Propinsi Lampung, 2009).

Perubahan penutup lahan merupakan keadaan suatu lahan yang karena manusia mengalami kondisi yang berubah pada waktu yang berbeda (Lillesand dkk, 2003). Lahan sendiri merupakan materi dasar dari suatu lingkungan, yang diartikan dengan sejumlah karakteristik alami, yaitu iklim, geologi tanah, topografi, hidrologi dan biologi (Aldrich, 1981 dalam Lo, 1995). Penutup lahan (land cover) adalah objek fisik yang menutup permukaan tanah yang meliputi vegetasi (alami maupun buatan), bangunan buatan manusia, tubuh air, es, batuan dan permukaan pasir (padang pasir). Menurut Darmawan (2002), salah satu faktor yang menyebabkan terjadinya perubahan tutupan hutan adalah faktor sosial ekonomi masyarakat yang berhubungan dengan kebutuhan hidup manusia terutama masyarakat sekitar hutan.

Perubahan tutupan hutan di Tahura WAR terjadi setiap tahunnya, oleh karena itu data dan informasi mengenai perubahan tutupan hutan di Tahura WAR sangat diperlukan sebagai pertimbangan pengambilan keputusan untuk pengelolaan kawasan hutan. Penginderaan jauh (remote sensing) merupakan salah satu teknologi yang dapat diterapkan untuk memperoleh data dan informasi mengenai penutup lahan di Tahura WAR. Teknologi ini menggunakan citra satelit sebagai data untuk ditafsir menjadi data spasial dan dikelola dalam bentuk basis data melalui Sistem Informasi Geografis (SIG). Analisis perubahan penggunaan lahan dengan memanfaatkan data spasial yang bersifat temporal sangat bermanfaat, khususnya untuk mengetahui lokasi-lokasi tempat dimana perubahan penggunaan lahan terjadi. Selain itu pemanfaatan Sistem Informasi Geografi (SIG) yang dapat mengintegrasikan data spasial dan data keruangan ternyata mampu menghasilkan data atribut yang bisa digunakan sebagai acuan dalam analisis statistik yang bisa digunakan untuk memprediksi luasan penggunaan lahan di masa datang (Assyakur dkk, 2010).

Tujuan penelitian ini adalah menganalisis luas perubahan tutupan hutan di Tahura WAR tahun 1994, 1997, 2000, 2014 dan aktifitas masyarakat terkait perubahan tutupan hutan di Tahura WAR.

\section{METODE PENELITIAN}

\section{Lokasi dan Waktu Penelitian}

Penelitian dilaksanakan di Taman Hutan Raya Wan Abdul Rachman (Tahura WAR). Berdasarkan administrasi pemerintahan Provinsi Lampung kawasan ini berada di Kota Bandar Lampung dan Kabupaten Pesawaran. Penelitian dilakukan selama tiga bulan, yakni pada bulan Maret sampai dengan bulan Juni 2013. 


\section{Alat dan BahanPenelitian}

Alat yang digunakan dalam penelitian yaitu GPS (global positioning sistem), kamera, alat tulis, dan seperangkat komputer yang dilengkapi dengan paket Sistem Informasi Geografis termasuk software Arcview 3.3 dan Erdas Imagine 9.1.

Bahan penelitian yang digunakan dalam pelaksanaan penelitian adalah Peta Tata Batas Kawasan Tahura WAR, citra Landsat Thematic Mapper (TM), Enhanced Thematic Mapper (ETM+), dan Onboard Operational Land Imager (OLI) yang diambil pada tahun 1994, 1997 , 2000, dan 2014, serta data Blok Pengelolaan Kawasan Tahura WAR.

Pengumpulan data dilakukan dengan cara:

1. Mengunduh citra Landsat TM, ETM+, dan OLI dari laman www.glovis.usgs.com.

2. Pengamatan langsung di lapangan untuk mengetahui keadaan Tahura WAR dan melakukan ground truth tutupan lahan.

3. Wawancara dengan responden, yaitu Ketua Gabungan Kelompok Tani Hutan (Gapoktan) setempat dan pelaku sejarah untuk memperoleh data mengenai sejarah perubahan penggunaan lahan.

Studi Pustaka, yaitu menyeleksi pustaka dan mengutip teori dan data yang berasal dari buku dan tulisan-tulisan lain yang berkaitan dengan penelitian ini.

\section{Metode dan Cara Kerja}

\section{Pemasukan Data}

Pemasukan data dilakukan dengan bantuan seperangkat komputer yang dilengkapi dengan perangkat lunak Erdas Imagine 9.1dan Arc View 3.3 yang menghasilkan keluaran berupa data digital tutupan lahan Tahura WAR. Data ini digunakan sebagai acuan wilayah penelitian dan koreksi geometrik pada pengolahan citra.

\section{Pengolahan citra}

Tahap pengolahan citra melalui analisis data digital meliputi proses awal (preprosessing), penajaman citra (image enhancement) dan klasifikasi citra (image classification). Penajaman citra (image enhancement) dilakukan untuk mendapatkan tampakan yang kontras sehingga memudahkan dalam proses interpretasi. Kemudian klasifikasi citra (image classification) dilakukan dengan metode maximum likelihood. Untuk mendapatkan ketelitian atau validasi citra kelompok penutup lahan dilakukan pencocokan dengan kondisi lapangan (ground truth). Bagian akhir pemrosesan citra adalah melakukan analisis sistem informasi geografi yang mencakup editing (memperbaiki kesalahan pada coverage), labeling (pemberian identitas/label setiap poligon, garis, atau titik), atributing (pemberian atribut atau informasi) dan topologi. Untuk mengetahui historis perubahan penutup lahan, dilakukan analisis teknik tumpang-tindih (overlay) hasil klasifikasi citra landsat TM, ETM+, dan OLI. Output hasil overlay tutupan lahan disajikan dalam bentuk layout peta perubahan tutupan lahan dan tabulasi. Selanjutnya, memberikan ulasan atau interpretasi terhadap data yang diperoleh sehingga menjadi lebih jelas dan bermakna dibandingkan dengan sekedar angka-angka. Langkah-langkahnya adalah reduksi data, penyajian data dengan bagan dan teks, kemudian penarikan kesimpulan.

Tahap-tahap pengolahan yang dilakukan sebagai berikut. 


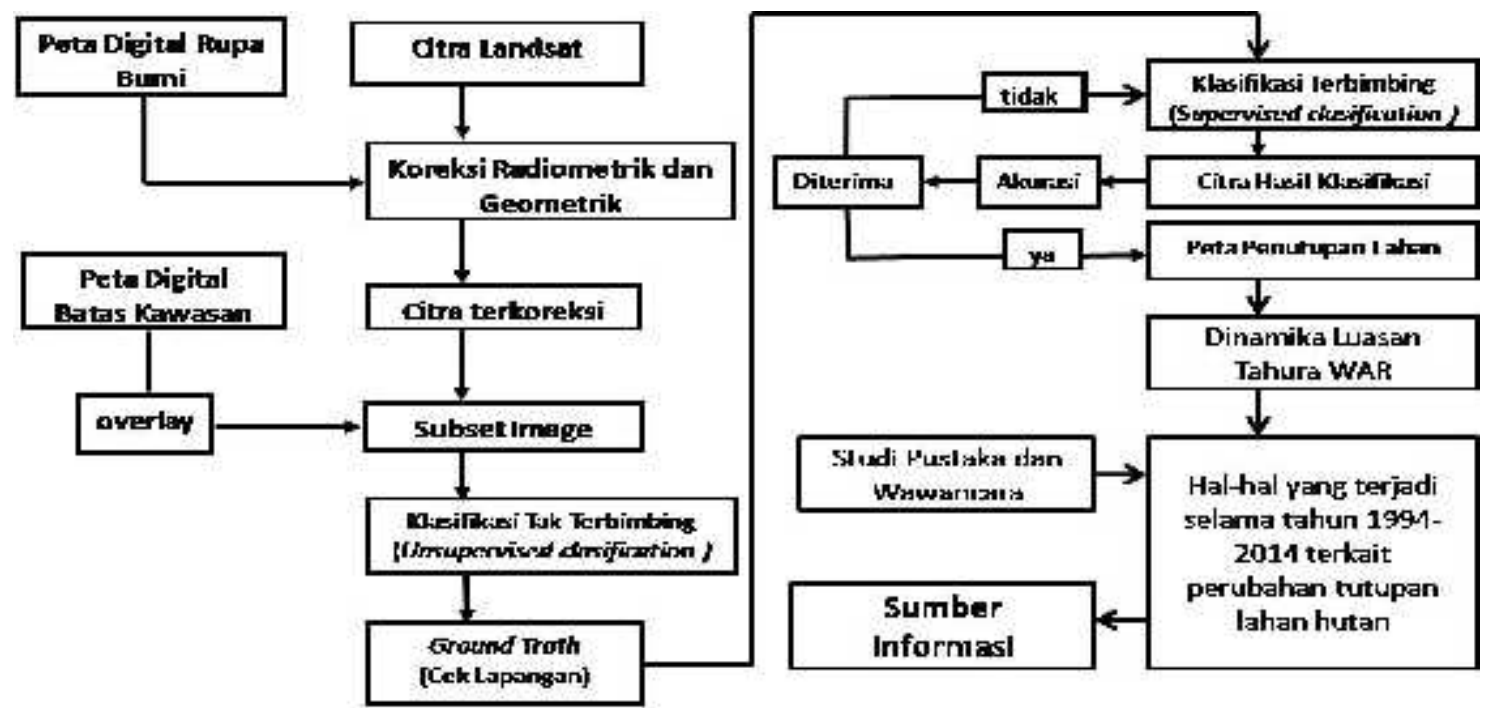

Gambar 1. Skema alur penelitian

\section{HASIL DAN PEMBAHASAN}

Kawasan Tahura WAR diklasifikasikan ke dalam lima tipe penutup lahan. Pembagian kelas bedasarkan pengamatan dilapangan dan citra landsat. Kelas-kelas tersebut adalah hutan, agroforestri, lahan terbuka, semak, dan tidak ada data (No Data). Sinaga dkk (2014) dalam penelitiannya, membagi kelas tutupan lahan Resort Pugung Tampak Taman Nasional Bukit Barisan Selatan menjadi 5 kelas, yaitu kelas tutupan hutan lahan kering primer, hutan lahan kering sekunder, pertatanian lahan kering, lahan terbuka, dan no data.

Berdasarkan hasil klasifikasi citra satelit Landsat tahun 1994, 1997, 2000, dan 2014, wilayah Tahura WAR mengalami perubahan penutup lahan pada setiap tipe tutupan lahannya. Dalam kurun waktu 1994-2014 telah terjadi peningkatan dan penurunan luas wilayah tutupan hutan yang terdapat dalam kawasan Tahura WAR. Perubahan tersebut dapat dilihat dalam Tabel 1.

Tabel 1. Perubahan luasan tutupan hutan di Taman Hutan Raya Wan Abdul Rachman.

\begin{tabular}{llrrrrr}
\hline \multirow{2}{*}{ No } & \multirow{2}{*}{ Tahun } & \multicolumn{2}{c}{ Luas Tutupan Lahan Hutan } & \multicolumn{2}{c}{ Besar Perubahan } & \multicolumn{2}{c}{ Akurasi Citra } \\
\cline { 3 - 6 } & & (ha) & $(\%)$ & (ha) & (\%) & $(\%)$ \\
\hline 1 & 1994 & 9090.11 & 40.9 & & & 98,33 \\
2 & 1997 & 6288.71 & 28.3 & -2801.39 & -30.82 & 92,50 \\
3 & 2000 & 5428.74 & 24.4 & -859.96 & -13.67 & 94,17 \\
4 & 2014 & 8952.98 & 40.2 & +3524.23 & +64.92 & 97.50 \\
\hline
\end{tabular}

Tingkat minimum ketelitian interpretasi menggunakan data penginderaan jauh harus setidaknya $85 \%$ Lillesand dkk (2003). Jaya dkk (2000) dalam penelitiannya mendapatkan nilai akurasi lebih dari $90 \%$ dari tiga citra yang telah diuji akurasi klasifikasinya, yakni sebesar 97.76\%, 97.44, dan 91.3\%.

Hasil overlay klasifikasi citra landsat menunjukkan perubahan tutupan lahan pada tahun 1994-2014 terjadi dengan dinamis, perubahan tutupan lahan terjadi pada hampir setiap kelas tutupan lahan. Hasil overlay klasifikasi citra tahun 1994-2014 menunjukan bahwa tutupan hutan mengalami penurunan sebesar 137,13 ha $(0.62 \%)$, agroforestri mengalami peningkatan luas tutupan lahan sebesar 345,46 ha (1,55\%), lahan terbuka sebesar 86,79 ha $(0.39 \%)$, dan semak mengalami penurunan sebesar 121,53 ha $(0.55 \%)$, sedangkan untuk tutupan lahan $N o$ Data memiliki luas tiap tahunnya $8.476,18$ ha $(38,1 \%)$. Perubahan tutupan lahan dari tahun 1994, 1997, 2000, dan 2014 disajikan berturut-turut pada Tabel 2, 3, dan 4. 
Tabel 2. Perubahan bentuk dan luas tutupan lahan di Tahura WAR tahun 1994-1997.

\begin{tabular}{|c|c|c|c|c|c|c|c|c|c|c|c|c|c|}
\hline & & \multicolumn{10}{|c|}{ Tahun 1994} & \multirow{2}{*}{\multicolumn{2}{|c|}{$\begin{array}{c}\text { PerubahanTutupan } \\
\text { Lahan }\end{array}$}} \\
\hline \multicolumn{2}{|c|}{ Kelas tutupan lahan } & \multicolumn{2}{|c|}{ Hutan } & \multicolumn{2}{|c|}{ Agroforestri } & \multicolumn{2}{|c|}{ Lahan Terbuka } & \multicolumn{2}{|c|}{ Semak } & \multicolumn{2}{|c|}{ Total } & & \\
\hline & & (ha) & (\%) & (ha) & (\%) & (ha) & $(\%)$ & (ha) & $(\%)$ & (ha) & (\%) & (ha) & (\%) \\
\hline \multirow{5}{*}{ 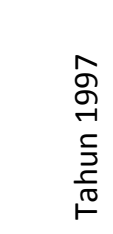 } & Hutan & $4,877.52$ & 21.92 & $1,156.84$ & 5.20 & 79.07 & 0.36 & 175.29 & 0.79 & $6,288.71$ & 28.26 & $-2,840.20$ & -12.77 \\
\hline & Agroforestri & $2,781.94$ & 12.50 & $1,853.40$ & 8.33 & 322.66 & 1.45 & 71.07 & 0.32 & $5,029.07$ & 22.60 & $1,494.82$ & 6.72 \\
\hline & Lahan Terbuka & $1,043.76$ & 4.69 & 414.06 & 1.86 & 175.76 & 0.79 & 65.98 & 0.30 & $1,699.56$ & 7.64 & $1,086.16$ & 4.88 \\
\hline & Semak & 425.69 & 1.91 & 109.96 & 0.49 & 35.91 & 0.16 & 184.22 & 0.83 & 755.78 & 3.40 & 259.22 & 1.17 \\
\hline & Total & $9,128.92$ & 41.03 & $3,534.25$ & 15.88 & 613.40 & 2.76 & 496.56 & 2.23 & $13,773.13$ & 61.90 & & \\
\hline
\end{tabular}

Tabel 3. Perubahan bentuk dan luas tutupan lahan di Tahura WAR tahun 1997-2000.

\begin{tabular}{|c|c|c|c|c|c|c|c|c|c|c|c|c|c|}
\hline \multirow{3}{*}{\multicolumn{2}{|c|}{ Kelas tutupan lahan }} & \multicolumn{10}{|c|}{ Tahun 1997} & \multirow{2}{*}{\multicolumn{2}{|c|}{$\begin{array}{c}\text { PerubahanTutupan } \\
\text { Lahan }\end{array}$}} \\
\hline & & \multicolumn{2}{|c|}{ Hutan } & \multicolumn{2}{|c|}{ Agroforestri } & \multicolumn{2}{|c|}{ Lahan Terbuka } & \multicolumn{2}{|c|}{ Semak } & \multicolumn{2}{|c|}{ Total } & & \\
\hline & & (ha) & $(\%)$ & (ha) & (\%) & (ha) & (\%) & (ha) & $(\%)$ & (ha) & $(\%)$ & (ha) & (\%) \\
\hline \multirow{5}{*}{ 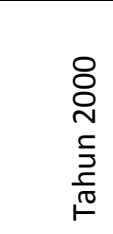 } & Hutan & $3,898.24$ & 17.52 & $1,178.76$ & 5.30 & 262.65 & 1.18 & 89.09 & 0.40 & $5,428.74$ & 24.40 & -971.69 & -4.37 \\
\hline & Agroforestri & $1,965.05$ & 8.83 & $3,802.22$ & 17.09 & 927.09 & 4.17 & 135.50 & 0.61 & $6,829.86$ & 30.70 & $1,233.98$ & 5.55 \\
\hline & Lahan Terbuka & 257.90 & 1.16 & 309.09 & 1.39 & 97.27 & 0.44 & 14.81 & 0.07 & 679.07 & 3.05 & -684.09 & -3.07 \\
\hline & Semak & 279.24 & 1.26 & 305.81 & 1.37 & 76.14 & 0.34 & 174.26 & 0.78 & 835.46 & 3.75 & 421.80 & 1.90 \\
\hline & Total & $6,400.43$ & 28.77 & $5,595.88$ & 25.15 & $1,363.16$ & 6.13 & 413.66 & 1.86 & $13,773.13$ & 61.90 & & \\
\hline
\end{tabular}

Tabel 4. Perubahan bentuk dan luas tutupan lahan di Tahura WAR tahun 2000-2014.

\begin{tabular}{|c|c|c|c|c|c|c|c|c|c|c|c|c|c|}
\hline \multirow{3}{*}{\multicolumn{2}{|c|}{ Kelas tutupan lahan }} & \multicolumn{10}{|c|}{ Tahun 2000} & \multirow{2}{*}{\multicolumn{2}{|c|}{$\begin{array}{c}\text { PerubahanTutupan } \\
\text { Lahan }\end{array}$}} \\
\hline & & \multicolumn{2}{|c|}{ Hutan } & \multicolumn{2}{|c|}{ Agroforestri } & \multicolumn{2}{|c|}{ Lahan Terbuka } & \multicolumn{2}{|c|}{ Semak } & \multicolumn{2}{|c|}{ Total } & & \\
\hline & & (ha) & $(\%)$ & (ha) & $(\%)$ & (ha) & $(\%)$ & (ha) & (\%) & (ha) & (\%) & (ha) & (\%) \\
\hline \multirow{5}{*}{ 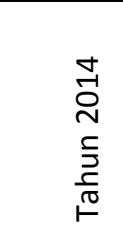 } & Hutan & $3,960.00$ & 17.80 & $4,143.88$ & 18.62 & 362.20 & 1.63 & 486.89 & 2.19 & $8,952.98$ & 40.24 & $3,659.74$ & 16.45 \\
\hline & Agroforestri & $1,132.44$ & 5.09 & $2,413.27$ & 10.85 & 157.41 & 0.71 & 188.64 & 0.85 & $3,891.76$ & 17.49 & $-3,230.28$ & -14.52 \\
\hline & Lahan Terbuka & 84.21 & 0.38 & 353.19 & 1.59 & 59.38 & 0.27 & 44.58 & 0.20 & 541.36 & 2.43 & -59.35 & -0.27 \\
\hline & Semak & 116.57 & 0.52 & 211.71 & 0.95 & 21.72 & 0.10 & 37.04 & 0.17 & 387.04 & 1.74 & -370.12 & -1.66 \\
\hline & Total & $5,293.23$ & 23.79 & $7,122.04$ & 32.01 & 600.71 & 2.70 & 757.15 & 3.40 & $13,773.13$ & 61.90 & & \\
\hline
\end{tabular}


Pada periode tahun 1994-1997 yang disajikan pada Tabel 2 menunjukkan penurunan tutupan lahan hanya terjadi pada tutupan hutan, yaitu sebesar 2.840 .2 ha $(12,8 \%)$ dan pada tutupan lahan lainnya mengalami peningkatan yaitu tutupan agroforestri $1.494,8$ ha $(6,7 \%)$, tutupan lahan terbuka 1.086,2 ha (4,9\%), dan tutupan semak sebesar 259,2 ha $(1,2 \%)$. Perubahan terbesar terjadi pada tutupan hutan menjadi agroforestri yakni sebesar 2.781,9 atau $12,5 \%$. Sedangkan untuk perubahan terkecil terjadi pada tutupan lahan terbuka menjadi tutupan lahan semak sebesar 35,9 ha atau 0,2 \%. Luas No Data sebesar 8.476,2 ha $(38,1 \%)$.

Pada Tabel 3, yakni periode tahun 1997-2000 tutupan hutan masih mengalami penurunan sebesar 971,7 ha $(4,4 \%)$ diikuti tutupan lahan terbuka sebesar 684,1 ha $(3,1 \%)$. Sedangkan untuk tutupan agroforestri mengalami peningkatan 1.234 ha $(5,6 \%)$ diikuti tutupan semak sebesar 421,8 ha $(1,9 \%)$. Perubahan tutupan lahan terbesar terjadi pada tutupan hutan menjadi agroforestri yaitu sebesar $1.965,1$ ha $(8,8 \%)$ dan untuk perubahan tutupan lahan terkecil terjadi pada tutupan lahan semak menjadi tutupan lahan terbuka sebesar 14,8 ha $(0.1 \%)$.

Hasil overlay yang terakhir tersaji pada Tabel 4. Pada periode 2000-2014 tutupan hutan mengalami peningkatan yang signifikan yakni sebesar 3.659,7 ha (16,5\%). Sedangkan untuk tutupan agroforestri, lahan terbuka, dan semak berturut-turut mengalami penurunan sebesar $3.230,3$ ha $(14,5 \%), 59,4$ ha $(0,3 \%)$, dan 370,1 ha $(1,7 \%)$. Tutupan agroforestri pada periode 2000-2014 mengalami perubahan terbesar menjadi tutupan hutan sebesar 4.143,9 ha $(18,625 \%)$. Perubahan tutupan lahan terbuka menjadi tutupan semak sebesar 21,7 ha $(0,1 \%)$ merupakan perubahan terkecil pada periode ini.

Perubahan tutupan hutan di Tahura WAR menunjukan hasil yang positif, dimana pada periode tahun 2000-2014 atau periode terakhir menunjukkan peningkatan yang signifikan. Sinaga dkk (2014) mengalami perubahan tutupan hutan yang selalu menurun dari periode 1973-2011. Hasil overlay klasifikasi citra tahun 1973-1997 Resort Pugung Tampak Taman Nasional Bukit Barisan Selatan menunjukan bahwa hutan lahan kering primer mengalami penurunan luas tutupan lahan sebesar $2.139,5$ ha $(44,1 \%)$, periode tahun 1997-2002 perubahan tutupan lahan hutan lahan kering primer menjadi lahan terbuka merupakan perubahan tutupan lahan paling besar yaitu sebesar $1.677,4$ ha $(9,7 \%)$, dan pada periode tahun 2002-2011 luas hutan lahan kering primer mengalami penurunan tutupan lahan sebesar 4.703,5 (36,0\%) ha. Daruati (2008) menyimpulkan hutan dan sawah merupakan penggunaan lahan yang relatif berkurang dari tahun ke tahun di DAS Cimanuk, hutan tersebut berubah menjadi kebun campuran, ladang, kebun sayur, tanah terbuka. Penelitian lainnya yang dilakukan oleh Riyanto (2010) menyebutkan Kawasan Semenanjung Santigi dalam kurun 5 tahun (2001-2005) telah mengalami kehilangan hutan sebanyak $2.096,23$ ha $(60,04 \%)$ dengan laju kehilangan mencapai 419,25 ha/tahun.

Penutupan lahan di kawasan Taman Hutan Raya Wan Abdul Rachman sudah seharusnya didominasi oleh tutupan lahan hutan, karena kawasan ini merupakan salah satu kawasan yang berfungsi sebagai areal konservasi sumberdaya alam hayati. Efisiensi dan efektifitas pengelolaan Tahura WAR dilakukan dengan membagi kawasan Tahura WAR menjadi beberapa blok pengelolaan, yaitu blok perlindungan, blok pemanfaatan, blok koleksi, dan blok lainnya (pendidikan, penelitian, dan social forestry (Dinas Kehutanan Propinsi Lampung, 2009). Hasil analisis citra menunjukkan bahwa blok pada Tahura WAR telah mengalami degadrasi. Perubahan tutupan lahan yang terjadi pada blok-blok di Tahura WAR menunjukkan ketidaksesuaian penggunan lahan dengan fungsi blok tersebut. Data perubahan lahan tiap blok dapat dilihat pada Tabel 5, 6, 7, dan 8 . 
Jurnal Sylva Lestari

Vol. 3 No. 2, Mei 2015 (43-52)

ISSN 2339-0913

Tabel 5. Perubahan tutupan lahan Blok perlindungan.

\begin{tabular}{|c|c|c|c|c|c|c|c|c|c|c|c|c|c|}
\hline \multirow{3}{*}{ No } & \multirow{3}{*}{ Tahun } & \multicolumn{12}{|c|}{ Kelas Tutupan Lahan } \\
\hline & & \multirow{2}{*}{$\begin{array}{l}\text { Hutan } \\
\text { (ha) }\end{array}$} & \multicolumn{2}{|c|}{ Perubahan } & \multirow{2}{*}{$\begin{array}{c}\text { Agroforestri } \\
\text { (ha) }\end{array}$} & \multicolumn{2}{|c|}{ Perubahan } & \multirow{2}{*}{$\frac{\text { LahanTerbuka }}{\text { (ha) }}$} & \multicolumn{2}{|c|}{ Perubahan } & \multirow{2}{*}{$\begin{array}{l}\text { Semak } \\
\text { (ha) }\end{array}$} & \multicolumn{2}{|c|}{ Perubahan } \\
\hline & & & (ha) & $(\%)$ & & (ha) & $(\%)$ & & (ha) & $(\%)$ & & (ha) & $(\%)$ \\
\hline 1 & 1994 & $3.211,98$ & & & $1.124,36$ & & & 419,49 & & & 181,20 & & \\
\hline 2 & 1997 & $3.598,53$ & $+386,55$ & $+12,03$ & 961,06 & $-163,3$ & $-14,52$ & 59,39 & $-360,1$ & $-85,84$ & 318,05 & $+136,85$ & $+75,52$ \\
\hline 3 & 2000 & $3.209,42$ & $-389,11$ & $-10,81$ & $1.152,57$ & $+191,51$ & $+19,93$ & 406,75 & $+347,36$ & $+584,88$ & 168,29 & $-149,76$ & $-47,09$ \\
\hline 4 & 2014 & $3.088,26$ & $-121,16$ & $-3,78$ & $1.582,38$ & $+429,81$ & $+37,29$ & 96,88 & $-309,87$ & $-76,18$ & 169,52 & $+1,23$ & $+0,73$ \\
\hline
\end{tabular}

Tabel 6. Perubahan tutupan lahan Blok Pemanfaatan.

\begin{tabular}{|c|c|c|c|c|c|c|c|c|c|c|c|c|c|}
\hline \multirow{3}{*}{ No } & \multirow{3}{*}{ Tahun } & \multicolumn{12}{|c|}{ Kelas Tutupan Lahan } \\
\hline & & \multirow{2}{*}{$\begin{array}{l}\text { Hutan } \\
\text { (ha) }\end{array}$} & \multicolumn{2}{|c|}{ Perubahan } & \multirow{2}{*}{$\frac{\text { Agroforestri }}{\text { (ha) }}$} & \multicolumn{2}{|c|}{ Perubahan } & \multirow{2}{*}{$\frac{\text { LahanTerbuka }}{\text { (ha) }}$} & \multicolumn{2}{|c|}{ Perubahan } & \multirow{2}{*}{$\frac{\text { Semak }}{\text { (ha) }}$} & \multicolumn{2}{|c|}{ Perubahan } \\
\hline & & & (ha) & $(\%)$ & & (ha) & $(\%)$ & & (ha) & $(\%)$ & & (ha) & $(\%)$ \\
\hline 1 & 1994 & 291,16 & & & 102,03 & & & 42,54 & & & 0,05 & & \\
\hline 2 & 1997 & 151,31 & $-139,85$ & $-48,03$ & 171,76 & $+69,73$ & $+68,34$ & 110,11 & $+67,57$ & $+158,84$ & 2,61 & $+2,56$ & +5.120 \\
\hline 3 & 2000 & 73,11 & $-78,2$ & $-51,68$ & 320,11 & $+148,35$ & $+86,37$ & 24,71 & $-85,4$ & $-77,56$ & 17,86 & $+15,25$ & $+584,29$ \\
\hline 4 & 2014 & 316,84 & $+243,73$ & $+333,37$ & 96,27 & $-223,84$ & $-69,93$ & 9,46 & $-15,25$ & $-61,72$ & 13,22 & $-4,64$ & $-25,98$ \\
\hline
\end{tabular}

Tabel 7. Perubahan tutupan lahan Blok Koleksi.

\begin{tabular}{|c|c|c|c|c|c|c|c|c|c|c|c|c|c|}
\hline \multirow{3}{*}{ No } & \multirow{3}{*}{ Tahun } & \multicolumn{12}{|c|}{ Kelas Tutupan Lahan } \\
\hline & & \multirow{2}{*}{$\frac{\text { Hutan }}{\text { (ha) }}$} & \multicolumn{2}{|c|}{ Perubahan } & \multirow{2}{*}{$\frac{\text { Agroforestri }}{\text { (ha) }}$} & \multicolumn{2}{|c|}{ Perubahan } & \multirow{2}{*}{$\frac{\text { LahanTerbuka }}{\text { (ha) }}$} & \multicolumn{2}{|c|}{ Perubahan } & \multirow{2}{*}{$\begin{array}{l}\text { Semak } \\
\text { (ha) }\end{array}$} & \multicolumn{2}{|c|}{ Perubahan } \\
\hline & & & (ha) & $(\%)$ & & (ha) & $(\%)$ & & (ha) & $(\%)$ & & (ha) & $(\%)$ \\
\hline 1 & 1994 & 265,78 & & & 158,39 & & & 89,68 & & & 0,36 & & \\
\hline 2 & 1997 & 271,82 & $+6,04$ & $+2,27$ & 229,83 & $+71,44$ & $+45,10$ & 10,02 & $-79,66$ & $-88,83$ & 2,54 & $+2,18$ & $+605,56$ \\
\hline 3 & 2000 & 64,03 & $-207,79$ & $-76,44$ & 261,56 & $+31,73$ & $+13,81$ & 117,94 & $+107,92$ & $+1.077,05$ & 70,69 & $+68,15$ & $+2.683,1$ \\
\hline 4 & 2014 & 385,94 & $+321,91$ & $+502,75$ & 60,01 & $-201,55$ & $-77,06$ & 47,95 & $-69,99$ & $-59,34$ & 20,31 & $-50,38$ & $-71,27$ \\
\hline
\end{tabular}

Tabel 8. Perubahan tutupan lahan Blok Lainnya.

\begin{tabular}{|c|c|c|c|c|c|c|c|c|c|c|c|c|c|}
\hline \multirow{3}{*}{ No } & \multirow{3}{*}{ Tahun } & \multicolumn{12}{|c|}{ Kelas Tutupan Lahan } \\
\hline & & \multirow{2}{*}{$\begin{array}{l}\text { Hutan } \\
\text { (ha) }\end{array}$} & \multicolumn{2}{|c|}{ Perubahan } & \multirow{2}{*}{$\begin{array}{c}\text { Agroforestri } \\
\text { (ha) }\end{array}$} & \multicolumn{2}{|c|}{ Perubahan } & \multirow{2}{*}{$\frac{\text { LahanTerbuka }}{\text { (ha) }}$} & \multicolumn{2}{|c|}{ Perubahan } & \multirow{2}{*}{$\frac{\text { Semak }}{\text { (ha) }}$} & \multicolumn{2}{|c|}{ Perubahan } \\
\hline & & & $\overline{\text { (ha) }}$ & (\%) & & (ha) & $(\%)$ & & (ha) & (\%) & & (ha) & $(\%)$ \\
\hline 1 & 1994 & $5.049,12$ & & & $2.358,95$ & & & 452,51 & & & 209,61 & & \\
\hline 2 & 1997 & $3.028,26$ & $-2020,86$ & $-40,02$ & $3.565,53$ & $+1206,58$ & $+51,15$ & $1.050,63$ & $+598,12$ & $+132,18$ & 425,78 & $+216,17$ & $+103,13$ \\
\hline 3 & 2000 & $3.097,24$ & $+68,98$ & $+2,28$ & $3.124,56$ & $-440,97$ & $-12,37$ & 837,31 & $-213,32$ & $-20,30$ & $1.011,08$ & $+585,3$ & $+137,47$ \\
\hline 4 & 2014 & $4.890,76$ & $+1793,52$ & $+57,91$ & $2.443,63$ & $-680,93$ & $-21,79$ & 441,18 & $-396,13$ & $-47,31$ & 294,63 & $-716,45$ & $-70,86$ \\
\hline
\end{tabular}


Tutupan lahan pada setiap blok pengelolaan di Tahura WAR telah mengalami perubahan dari periode tahun 1994, 1997, 2000, dan 2014. Blok perlindungan mengalami perubahan luas tutupan hutan terbesar pada periode tahun 1997-2000, yaitu berkurang sebesar 389,11 ha $(10,81 \%)$. Bersamaan dengan berkurangnya tutupan hutan pada blok perlindungan, tutupan agraforestri meningkat pada periode yang sama sebesar 191,5 ha (19,9\%) dan 429,8 ha $(37,3 \%)$. Tutupan hutan pada blok pemanfaatan bertambah 243,73 ha $(333,37 \%)$ dari periode tahun 2000-2014, blok koleksi bertambah 321,91 ha $(502,75 \%)$ dari periode tahun 2000-2014, dan blok lainnya mengalami perubahan tutupan hutan terbesar pada peride 19941997, yakni berkurang sebesar 2020,86 ha (40,02\%) dan pada periode tahun 2000-2014 meningkat sebesar 1793,52 ha $(57,91 \%)$. Perubahan tutupan hutan terjadi pada setiap blok pengelolaan di Tahura WAR tidak terkecuali pada blok perlindungan yang mengalami perubahan menjadi tutupan agroforestri dan semak sebesar 429,81 ha atau 37,29\% dan 1,23 ha atau 0,73\% pada periode tahun 2000-2014. Blok Perlindungan merupakan kawasan yang diperuntukkan untuk perlindungan jenis tumbuhan, satwa, dan ekosistem, serta diperuntukkan sebagai penyangga kehidupan. Pada dasarnya aktifitas pengelolaan lahan di dalam blok perlindung tidak diizinkan, namun hasil analilis citra landsat membuktikan bahwa blok perlindungan juga telah mengalami gangguan oleh aktifitas masyarakat.

\section{KESIMPULAN}

Penutupan lahan di Taman Hutan Raya Wan Abdul Rachman dibagi menjadi 5 tipe klasifikasi lahan yaitu hutan, agroforestri, lahan terbuka, semak, dan tidak ada data (No Data). Dalam kurun waktu 1994-2014, fluktuasi perubahan tutupan hutan terjadi pada setiap periode. Periode tahun 1994-1997 luas tutupan hutan menurun. Pada periode tahun berikutnya yakni tahun 1997-2000, luas tutupan hutan masih mengalami penurunan. Periode tahun 2000-2014 luasan tutupan hutan mengalami peningkatan.

Fluktuasi perubahan tutupan lahan didominasi oleh tutupan hutan dan agroforestri. Pada periode tahun1994-1997 penutupan lahan hutan mengalami perubahan penurunan terbesar menjadi agroforestri. Pada tahun 1997-2000 tutupan hutan masih mengalami pengurangan menjadi agroforestri. Sedangkan pada tahun 2000-2014 perubahan terbesar terjadi pada agroforestri menjadi tutupan hutan.

Faktor yang mempengaruhi perubahan penutupan lahan dalam kawasan Taman Hutan Raya Wan Abdul Rachman adalah adanya aktifitas manusia, perubahan status kawasan, dan kebijakan pemerintah. Aktifitas manusia dalam kawasan berupa perambahan hutan, illegal logging, dan perladangan.

\section{DAFTAR PUSTAKA}

Assyakur, A.R., I.W. Suarna., I.W.S. Adnyana., I.W. Rusna., I.A.A. Laksmiwati. dan I.W. Diara. 2010. Studi Perubahan Penggunaan di DAS Bandung. Jurnal Bumi Lestari. 10(2): 200-208.

Darmawan, A. 2002. Perubahan penutup lahan di Cagar Alam Rawa Danau. Skripsi. Institut Pertanian Bogor. Bogor. 46 p.

Daruati, D. 2008. Penggunaan citra landsat 7 ETM+ untuk kajian penggunaan lahan Das Cimanuk. Jurnal LIMNOTEK. XV(1): 40—50.

Dinas Kehutanan Provinsi Lampung. 2009. Buku Informasi Tahura. Bandar Lampung. 38 p.

Jaya, I .N.S., S. Hardjoprajitno. dan S.A. Jatmiko. 2000. Pemantauan perubahan vegetasi di daerah perkotaan menggunakan landsat TM di Jakarta. Jurnal Manajemen Hutan Tropika. 6(1): 33-42. 
Lillesand, T.M., R.W Kiefer. and J.W. Chipman. 2003. Remote Sensing and Image interpretation Fifth Edition. Buku. John Wiley \& Son. United States of America. 812 p.

Lo, C. P. 1995. Penginderaan Jauh Terapan. Terjemahan. Buku. Penerbit Universitas Indonesia. Jakarta. 393 p.

Pasya, G. dan M. T. Sirait. 2011. Analisis Gaya Bersengketa (AGATA): Panduan Ringkas Untuk Memilih Bentuk Penyelesaian Sengketa Pengelolaan Sumberdaya Alam. Buku. Bogor: The Samdhana Institute. 74 p.

Riyanto, A., S. Soemarno. dan A. Farajallah. 2010. Laju kehilangan dan kondisi terkini habitat Baning Sulawesi (Indotestudo forstenii) di Semenanjung Santigi, Sulawesi Tengah, Indonesia. Jurnal Biologi Indonesia. 6(2):185-194.

Sinaga, R.P. dan A. Darmawan. 2014. Perubahan tutupan lahan di Resort Pugung Tampak Taman Nasional Bukit Barisan Selatan (TNBBS). Jurnal Sylva Lestari. 2(1):77—86. 
Vol. 3 No. 2, Mei 2015 (43-52)

Halaman ini sengaja dikosongkan 